\title{
Cerium Separation from Light Rare Earth Concentrate by Liquid-Liquid Extraction
}

\author{
Thiago Silveira Formiga, Carlos Antonio de Morais* \\ Centro de Desenvolvimento da Tecnologia Nuclear (CDTN), Belo Horizonte, Brazil \\ Email: tsformiga@gmail.com, ${ }^{*}$ cmorais@cdtn.br
}

How to cite this paper: Formiga, T.S. and de Morais, C.A. (2016) Cerium Separation from Light Rare Earth Concentrate by Liquid-Liquid Extraction. World Journal of Engineering and Technology, 4, 129-137. http://dx.doi.org/10.4236/wjet.2016.43D016

Received: September 2, 2016 Accepted: October 13, 2016

Published: October 20, 2016

\begin{abstract}
This work presents an investigation of solvent extraction parameters in order to obtain high purity cerium from a mixture containing other rare earths elements, as an alternative to oxidation and selective precipitation or dissolution. The study was carried out using a sample of sulfuric liquor obtained from the leaching of monazite rich in light rare earth elements ( $\mathrm{La}, \mathrm{Ce}, \mathrm{Pr}, \mathrm{Nd}$ ) provided by INB (Indústrias Nucleares do Brasil S.A.). Experiments were carried out in chloridric, nitric and sulfuric media. The nitric and hydrochloric solutions were prepared by precipitation of the REE from the sulfuric liquor as rare earths oxalate, calcining the precipitate and dissolving it with nitric or hydrochloric acid. The separation of cerium was investigated in its trivalent and tetravalent forms. The parameters investigated were: type and concentration of extractant, type and amount of the oxidizing agent, liquor acidity, and volumetric ratio between organic and aqueous phases. The preference of the organic phase to extract cerium in its oxidized form (IV) over the other rare earths elements was confirmed, allowing the obtainment of a high purity cerium solution. The best results were achieved in nitric medium, with cerium in its tetravalent form, using cationic extractants (P507 or D2EHPA) and a mixture of potassium persulfate and silver chloride as oxidizing agents, yielding over $99 \%$ of cerium extraction with over $99 \%$ of purity.
\end{abstract}

\section{Keywords}

Cerium, Cerium Extraction, Cerium Oxidation, Rare Earths Elements

\section{Introduction}

Cerium is part of the group of rare earth elements (REE), which includes the 15 members of the lanthanides group (lanthanum, praseodymium cerium, neodymium, promethium, samarium, europium, gadolinium, terbium, dysprosium, holmium, erbium, 
thulium, ytterbium and lutetium) and yttrium and scandium. These elements are extremely important for cutting-edge technology industry, present in various products such as motor vehicles, catalysts for petroleum refining and emission treatment, permanent magnets, automotive rechargeable batteries, electronic components and components for wind turbines for generating electricity [1] [2].

The rare earth elements have very similar physical and chemical properties and therefore occur together in different proportions in their mineral sources. Obtaining the individual rare earth elements in industrial scale is very complex and only dominated by a few countries. To obtain the individual REE in high purity, first the liquor obtained from the ore chemical opening step must go through purification. This is usually performed by precipitation of REE as double sulfate of rare earths and sodium $\left(\mathrm{NaRE}\left(\mathrm{SO}_{4}\right)_{2}\right)$, or oxalate of rare earths $\left(\mathrm{RE}_{2}\left(\mathrm{C}_{2} \mathrm{O}_{4}\right)_{3}\right)$, being the precipitation of the double sulfate the most economical route [3]-[5].

Cerium is the only element in the RE series, which can be stable in oxidized form. The difference in solubility between hydroxides of Ce(IV) and the other trivalent rare earth elements is sufficiently high to obtain a good separation of the first as a hydroxide [6]. Generally, the separation of cerium is accomplished by the oxidation of $\mathrm{Ce}$ (III) to $\mathrm{Ce}(\mathrm{IV})$ following by the selective dissolution of the trivalent REEs. By this technique, the other REEs are usually contaminated with cerium or cerium is contaminated with other rare earth elements, depending of the desired purity of the product, therefore justifying the study of its separation by the solvent extraction technique [3].

After cerium removal, the other elements are usually separated by solvent extraction, initially separating them in groups: light ( $\mathrm{La}, \mathrm{Pr}, \mathrm{Nd})$, medium (Sm, Eu, Gd) and heavy (Tb, Dy, Ho, Er, Tm, Lu, Y Sc) [7].

Alternatively to this method, studies have been made in order to extract cerium(IV) selectively using liquid-liquid extraction. Zhang et al. investigated the formation of complexes of cerium(IV) fluoride in solution favouring the selective extraction of this metal in relation to other rare earth elements in a sulfuric acid medium and employing extractants such as P507, Cyanex ${ }^{\otimes} 923$ and Alamine ${ }^{\oplus} 336$ [8]. Zhao utilized a solution of ammonium persulfate and silver nitrate in cerium oxidation in nitric medium [9]. El-Nadi et al. used sodium bromate solution in nitric acid medium, to maintain the cerium in its tetravalent form [10].

The usual REE separation route yields a product of cerium contaminated with the the other trivalent rare earth elements [3]. This work proposes the selective separation of the cerium in its oxidized form by the liquid-liquid extraction technique, in order to obtain a cerium product of high purity and high recovery, yielding a solution of the other rare earth elements free of cerium in order to recover the other individual elements.

\section{Experimental}

\subsection{Reagents and Solutions}

The rare earth sample solution was provided by INB (Industrias Nucleares do Brasil). It's a sulfuric liquor, rich in light rare earth elements (lanthanum, cerium, praseodymium, neodymium), coming from the monaziteacid leaching, after previous removal of 
thorium and uranium according to a previous study [11]. For the experiments in nitric and hydrochloric media, the rare earth elements from the liquor were precipitated in rare earths oxalate form, calcined, forming rare earth oxides, and then dissolved in the respective acid. The REE concentrations of the liquors are shown in Table 1.

The organic solutions were prepared from the commercial concentrated extractants diluted in EXXSOLD100 (Exxon Chemicals Ltda.). The extractants used were: tri-nbutyl-phosphate-TBP (Baker Chemical Co.), trialkylphosphine oxide-Cyanex'923 (Cytec Industries Inc.), di-2-ethylhexyl phosphoric acid-D2EHPA (Albright \& Wilson Americas Inc), 2-ethylhexyl mono (2-ethylhexyl) ester phosphonic acid-P507 (Luoyang Aoda Chemical Co.), T-Alkyl (C16-C22) primary amine-Primene JMT (Dow Chemical), trioctyl/decyl amine-Alamine 336 and trialkyl-methyl-ammonium-chloride-Aliquat 336 (Cognis). In the amines solutions, 5\%vol of tridecanol (modifying agent) was added. All the other reagents were of analytical grade and their solutions were prepared with distilled water.

\subsection{Experiments}

The effects of the main process parameters, such as extraction medium, extractant type and concentration, aqueous phase acidity, volumetric ratio between the phases, and cerium oxidation state were investigated. The experiments were carried out in mechanically agitated beakers containing the aqueous and organic phases, at room temperature $\left(25^{\circ} \mathrm{C} \pm 1^{\circ} \mathrm{C}\right)$ and volumetric ratio between the organic and aqueous phases of 1 . After the contact, the phases were separated by using a separation funnel. All the experiments were carried out in a fixed time of $5 \mathrm{~min}$, based on the results of preliminary experiments, indicating that $3 \mathrm{~min}$ were sufficient to achieve equilibrium [12].

\section{Results and Discussion}

The extraction experiments were performed in two steps, in the presence and absence of oxidizing agents in order to verify the preferential extraction of cerium in its oxidized form. In each step cationic (P507 and D2EHPA), anionic (Primene JMT ${ }^{\oplus}$, Alamine ${ }^{\oplus 36}$ and Aliquat ${ }^{\circledR 336}$ ) and solvating (TBP and Cyanex ${ }^{923}$ ) extractants were investigated. For the first part, the three liquors were studied and then the sample in which the best results were achieved was carried on to the second part. The concentration used for the cationic and solvating extractants was $1.0 \mathrm{~mol} \cdot \mathrm{L}^{-1}$, and for the anionic extractants, $0.5 \mathrm{~mol} \cdot \mathrm{L}^{-1}$. After the extraction, stripping experiments were studied, using an organic solution from the extraction step and an aqueous stripping solution.

Table 1. Chemical composition of the rare earths liquors.

\begin{tabular}{cccccccccc}
\hline \multirow{2}{*}{ Sample } & \multicolumn{9}{c}{ Content $(\mathrm{g} / \mathrm{L})$} \\
\cline { 2 - 9 } & $\mathrm{La}$ & $\mathrm{Ce}$ & $\mathrm{Nd}$ & $\mathrm{Pr}$ & $\mathrm{Sm}$ & $\mathrm{Gd}$ & $\mathrm{Dy}$ & $\mathrm{Y}$ \\
\hline Sulphuric liquor & 6.7 & 14.8 & 5.6 & 1.5 & 0.69 & 0.56 & 0.16 & 0.49 \\
Hydrochloric liquor & 6.5 & 14.6 & 5.6 & 1.6 & 0.70 & 0.56 & 0.16 & 0.47 \\
Nitric liquor & 6.5 & 14.5 & 5.7 & 1.5 & 0.71 & 0.56 & 0.16 & 0.50 \\
\hline
\end{tabular}




\subsection{Extraction without Oxidizing Agents}

The experiments in sulfuric liquor were conducted at the sample's original acidity (1.2 mol. $\mathrm{L}^{-1} \mathrm{H}^{+}-\mathrm{pH}<0$ ) using anionic (basic), cationic (acid) and neutral (solvating) extractants. In the conditions investigated, no REE extraction was observed for none of the extractants, maybe due to the high acidity of the liquor. For the basic extractants, which extracts anionic species, it is probable that, in this condition, there was not anionic species formation, whereas for the cationic extractant, the extraction is not favoured due to the acidity of the liquor $\mathrm{H}$ adjustment was unfeasible due to formation of a precipitate of rare earth double sulfates with sodium or ammonium, depending on the base used $\left(\mathrm{NaOH}, \mathrm{NH}_{4} \mathrm{OH}\right.$ or $\left.\mathrm{Na}_{2} \mathrm{CO}_{3}\right)$.

The experiments carried out in hydrochloric medium were conducted at $\mathrm{pH} 1.0$ using neutral and cationic extractants. The solvating (neutral) extractants yielded no significant rare earth elements extraction (less than $3 \%$ for all elements). For cationic extractants the $\mathrm{pH}$ of the solution was varied from 0.5 to 2.0 and the equilibrium $\mathrm{pH}$ was maintained by addition of sodium hydroxide during the experiments. The results of the experiments using cationic extractants are shown in Table 2. A difference in behavior between the extractants is observed. Although both have shown preference for extracting the heavier rare earth elements first, P507 has a tendency to extract them with greater selectivity than D2EHPA, as seen by the higher separation factors for the same $\mathrm{pH}$. When using D2EHPA at $\mathrm{pH} 2.0$ the extractant starts to form an emulsion after the contact, hindering the separation of the phases. For both systems, the extraction of rare earth elements increases with the increase of $\mathrm{pH}$ in the studied range, also shown in Table 2, being D2EHPA a stronger extractant than P507.

At last, experiments were made using the nitric liquor, at $\mathrm{pH} 1.0$ and also adjusted with sodium hydroxide during the experiments to maintain the aqueous phase initial acidity. Tests using anionic extractants and TBP indicated no significant extraction of rare earth elements, with recoveries lower than $5 \%$ for all light REE. The results for the other extractants are shown in Table 3 below.

In the experimental conditions investigated, Cyanex 923 demonstrated a strong potential for extraction of REE in nitric medium, but it has no selectivity, extracting nearly all of the elements present in the solution. Both P507 and D2EHPA showed selectivity

Table 2. Influence of $\mathrm{pH}$ on $\mathrm{REE}$ extraction from hydrochloric liquor.

\begin{tabular}{cccccccccc}
\hline \multirow{2}{*}{ Extractant } & Initial pH & Final pH & \multicolumn{3}{c}{ Extraction (\%) } & \multicolumn{4}{c}{ Separation factor } \\
\cline { 5 - 9 } & & & La & Ce & Pr & Nd & Ce/La & Pr/Ce & Nd/Pr \\
\hline P507 & 0.5 & 0.5 & 0.7 & 1.8 & 6 & 7 & 3.5 & 3.2 & 1.2 \\
P507 & 1.0 & 1.0 & 5.0 & 16 & 37 & 40 & 3.9 & 3.2 & 1.2 \\
P507 & 2.0 & 1.9 & 13 & 37 & 66 & 70 & 4.1 & 3.2 & 1.2 \\
D2EHPA & 0.5 & 0.5 & 17 & 38 & 61 & 64 & 3.1 & 2.7 & 1.1 \\
D2EHPA & 1.0 & 1.0 & 36 & 64 & 80 & 82 & 3.2 & 2.3 & 1.1 \\
D2EHPA & 1.5 & 1.4 & 65 & 86 & 93 & 94 & 3.3 & 2.2 & 1.1 \\
\hline
\end{tabular}


Table 3. REE extraction from nitric liquor.

\begin{tabular}{cccccccc}
\hline \multirow{2}{*}{ Extractant } & \multicolumn{4}{c}{ Extraction (\%) } & \multicolumn{3}{c}{ Separation factor } \\
\cline { 2 - 7 } & $\mathrm{La}$ & $\mathrm{Ce}$ & $\mathrm{Pr}$ & $\mathrm{Nd}$ & $\mathrm{Ce} / \mathrm{La}$ & $\mathrm{Ce} / \mathrm{Pr}$ & $\mathrm{Nd} / \mathrm{Pr}$ \\
\hline Cyanex 923 & 98 & 100 & 99 & 99 & - & - & - \\
P507 & 7 & 76 & 34 & 36 & 44 & 6.2 & 1.1 \\
D2EHPA & 54 & 95 & 91 & 89 & 17 & 2.6 & 1.1 \\
\hline
\end{tabular}

in the extraction of cerium, extracting it preferentially to other elements, being the selectivity of the first higher. This preference can be explained by the presence of tetravalent cerium ions in solution which are extracted before the other trivalent elements. Although the experiments do not use oxidizing agents, the nitric medium itself is oxidizing, with potential to maintain the cerium oxidized during calcination of the rare earth oxalate in the tetravalent state. Under the conditions of the experiments, P507 showed better separation of cerium than D2EHPA.

After the preliminary experiments, the influence of the $\mathrm{pH}$ of the feed solution on the REE extraction was investigated. The results are shown in Table 4.

In all experiments there was a preferential extraction of cerium relative to the other REE. For the experimental conditions, when P507was used as extractant, pH 1.0 was the best condition for selectively extracting cerium, despite having a lower extraction yield than at $\mathrm{pH}$ 2.0, because lanthanum extraction increased more than cerium extraction at lower $\mathrm{pH}$. In experiments using D2EHPA, $\mathrm{pH} 0.5$ was the best acidity for the separation of cerium in the range studied, however its efficiency was much lower than that obtained for the P507. No selective extraction was observed for $\mathrm{Nd}$ and $\mathrm{Pr}$ in the conditions investigated (Table 4).

\subsection{Extraction in the Presence of Oxidizing Agents}

It is well known that in acidic medium the oxidation of cerium (III) to cerium (IV) requires the use of strong oxidants [3]. In the present study, the influence of ammonium persulfate- $\left(\mathrm{NH}_{4}\right)_{2} \mathrm{~S}_{2} \mathrm{O}_{8}$, sodium persulfate- $\mathrm{Na}_{2} \mathrm{~S}_{2} \mathrm{O}_{8}$, potassium persulfate $\mathrm{K}_{2} \mathrm{~S}_{2} \mathrm{O}_{8}$ on the $\mathrm{Ce}$ (III) oxidation was investigated. The oxidants were added until the potential stability.

The use of these oxidants in the sulfuric medium was unfeasible due to the precipitation of the rare earth elements as double sulfates in the aqueous phase. In order to minimize the extraction of trivalent REE, the influence of the oxidants in hydrochloric medium was investigated at the acidity of $1.0 \mathrm{~mol} \cdot \mathrm{L}^{-1} \mathrm{H}^{+}$. The experiments were carried out using sodium persulfate $\left(\mathrm{Na}_{2} \mathrm{~S}_{2} \mathrm{O}_{8}\right)$ and potassium persulfate $\left(\mathrm{K}_{2} \mathrm{~S}_{2} \mathrm{O}_{8}\right)$ as oxidants (0.5 mol. $\mathrm{L}^{-1}$ solution) and P507 and D2EHPA as extractants in a concentration of 1.0 mol L-1. The results in the presence of the investigated oxidants were compared with experiments carried out without oxidants using the same extractant concentrations, however in different aqueous phase acidity $\left(0.1 \mathrm{~mol} \cdot \mathrm{L}^{-1} \mathrm{H}^{+}-\mathrm{pH} 1.0\right)$, and without equilibrium $\mathrm{pH}$ correction (Table 5). As shown in Table 5, no selectivity in the extraction 
Table 4. Influence of $\mathrm{pH}$ on $\mathrm{REE}$ extraction from nitric liquor.

\begin{tabular}{cccccccccc}
\hline \multirow{2}{*}{ Extractant } & Initial pH & Final pH & \multicolumn{3}{c}{ Extraction (\%) } & \multicolumn{4}{c}{ Separation factor } \\
\cline { 5 - 10 } & & & $\mathrm{La}$ & $\mathrm{Ce}$ & $\mathrm{Pr}$ & $\mathrm{Nd}$ & $\mathrm{Ce} / \mathrm{La}$ & $\mathrm{Ce} / \mathrm{Pr}$ & $\mathrm{Nd} / \mathrm{Pr}$ \\
\hline P507 & 1.0 & 1.0 & 7 & 76 & 35 & 36 & 44 & 5.8 & 1.0 \\
P507 & 2.0 & 2.0 & 26 & 89 & 80 & 80 & 24 & 2.2 & 1.0 \\
D2EHPA & 0.5 & 0.5 & 25 & 88 & 69 & 69 & 22 & 3.4 & 1.0 \\
D2EHPA & 1.0 & 1.0 & 54 & 93 & 88 & 89 & 16 & 2.6 & 1.0 \\
D2EHPA & 1.5 & 1.5 & 86 & 99 & 98 & 98 & 20 & 2.2 & 1.0 \\
\hline
\end{tabular}

Table 5. Influence of oxidizing agents on REE extraction from hydrochloric liquor.

\begin{tabular}{|c|c|c|c|c|c|c|c|c|c|c|}
\hline \multirow{2}{*}{ Extractant } & \multirow{2}{*}{ Oxidant } & \multirow{2}{*}{$\begin{array}{c}\text { Initial } \\
(\mathrm{mV})\end{array}$} & \multirow{2}{*}{$\begin{array}{c}\text { Final } \\
\text { Potential } \\
(\mathrm{mV})\end{array}$} & \multicolumn{4}{|c|}{ Extraction (\%) } & \multicolumn{3}{|c|}{ Separation factor } \\
\hline & & & & $\mathrm{La}$ & $\mathrm{Ce}$ & $\operatorname{Pr}$ & $\mathrm{Nd}$ & $\mathrm{Ce} / \mathrm{La}$ & $\mathrm{Pr} / \mathrm{Ce}$ & $\mathrm{Nd} / \mathrm{Pr}$ \\
\hline$P 507$ & None $^{*}$ & 550 & 550 & 3 & 7 & 12 & 15 & 2.4 & 1.8 & 1.3 \\
\hline$P 507$ & $\mathrm{Na}_{2} \mathrm{~S}_{2} \mathrm{O}_{8}$ & 930 & 600 & 6 & 12 & 15 & 17 & 2.1 & 1.3 & 1.2 \\
\hline$P 507$ & $\mathrm{~K}_{2} \mathrm{~S}_{2} \mathrm{O}_{8}$ & 985 & 580 & 7 & 13 & 16 & 18 & 2.0 & 1.3 & 1.2 \\
\hline$D 2 E H P A$ & None ${ }^{\star *}$ & 550 & 540 & 11 & 22 & 30 & 32 & 2.4 & 1.5 & 1.1 \\
\hline$D 2 E H P A$ & $\mathrm{Na}_{2} \mathrm{~S}_{2} \mathrm{O}_{8}$ & 930 & 580 & 16 & 28 & 37 & 42 & 2.1 & 1.5 & 1.1 \\
\hline$D 2 E H P A$ & $\mathrm{~K}_{2} \mathrm{~S}_{2} \mathrm{O}_{8}$ & 985 & 600 & 16 & 27 & 38 & 39 & 2.0 & 1.5 & 1.1 \\
\hline
\end{tabular}

${ }^{*}$ Initial pH 1.0-final pH 0.7; **Initial pH 1.0-Final pH 0.5 .

of cerium was observed. It will be concluded that Ce (III) was not oxidized, or, if oxidized, it was reduced by the extractant. The increase in the REE extraction when oxidants were used is due to the dilution of the aqueous phase by the addition of the oxidants in solution form, as well as a slight decrease in the acidity after the addition of the oxidants.

In the evaluation of oxidants for the extraction of cerium (IV) in nitric medium, the extractants used were D2EHPA, P507 and Cyanex 923, which were the extractants that demonstrated the highest potential in the first stage of this study. The oxidizing agents studied were: ammonium persulfate $\left(\left(\mathrm{NH}_{4}\right)_{2} \mathrm{~S}_{2} \mathrm{O}_{8}\right)$, sodium persulfate $\left(\mathrm{Na}_{2} \mathrm{~S}_{2} \mathrm{O}_{8}\right)$, potassium persulfate $\left(\mathrm{K}_{2} \mathrm{~S}_{2} \mathrm{O}_{8}\right)$, silver nitrate $\left(\mathrm{AgNO}_{3}\right)$ and potassium permanganate $\left(\mathrm{KMnO}_{4}\right)$, as seen in other works [8]-[10] [13].

Initially potassium persulfate, silver nitrate, potassium permanganate and a mixture of silver nitrate with the other oxidants were investigated. The experimental conditions were extractant concentration of $1.0 \mathrm{~mol} \cdot \mathrm{L}^{-1}$, acidity of $2.0 \mathrm{~mol} \cdot \mathrm{L}^{-1}$ and ratio between the phases of 1 . Tests using potassium permanganate indicated the formation of an amorphous solid, probably $\mathrm{MnO}_{2}$, formed during the oxidation of cerium. The results of the other experiments are shown in Table 6.

It was observed that in all experiments cerium was extracted preferentially, including the experiment without the addition of any oxidant. This can be explained by the fact 
Table 6. Influence of oxidizing agents on REE extraction from nitric liquor.

\begin{tabular}{|c|c|c|c|c|c|c|c|}
\hline \multirow{2}{*}{ Oxidant } & \multirow{2}{*}{ Contact } & \multirow{2}{*}{$\begin{array}{l}\text { Initial EMF } \\
\qquad(\mathrm{mV})\end{array}$} & \multirow{2}{*}{$\begin{array}{l}\text { Final EMF } \\
\quad(\mathrm{mV})\end{array}$} & \multicolumn{4}{|c|}{ Extraction (\%) } \\
\hline & & & & $\mathrm{La}$ & $\mathrm{Ce}$ & $\operatorname{Pr}$ & $\mathrm{Nd}$ \\
\hline \multirow[b]{2}{*}{ None } & 1 st & 1460 & 950 & $<1$ & 45 & $<1$ & $<1$ \\
\hline & 2nd & 950 & 950 & $<1$ & 15 & $<1$ & $<1$ \\
\hline \multirow{2}{*}{$\mathrm{K}_{2} \mathrm{~S}_{2} \mathrm{O}_{8}$} & 1 st & 1460 & 1175 & $<1$ & 45 & $<1$ & $<1$ \\
\hline & 2nd & 1250 & 1230 & $<1$ & 16 & $<1$ & $<1$ \\
\hline \multirow{2}{*}{$\mathrm{AgNO}_{3}$} & 1 st & 1460 & 925 & $<1$ & 44 & $<1$ & $<1$ \\
\hline & 2nd & 1220 & 1200 & $<1$ & 19 & $<1$ & $<1$ \\
\hline \multirow{2}{*}{$\mathrm{K}_{2} \mathrm{~S}_{2} \mathrm{O}_{8}+\mathrm{AgNO}_{3}$} & 1 st & 1620 & 1410 & $<1$ & 95 & $<1$ & $<1$ \\
\hline & 2nd & 1410 & 950 & $<1$ & 5 & $<1$ & $<1$ \\
\hline
\end{tabular}

that nitric medium is oxidant, and may retain some of cerium which has been oxidized in the calcination stage of sample preparation in a +4 valence. It was also concluded that potassium persulfate and silver nitrate alone in solution do not provide an increase in the recovery of cerium, vs. the base case (no oxidant), but together provide a greater extraction of cerium, with a very low co-extraction of other REE.

Then extraction experiments were carried out using the raffinate (aqueous solution) of the previous experiments using the same conditions in a second contact, simulating a two-stage extraction. Exceptionally in the experiment with the mixture of oxidants, no more oxidant was added in this step, since the electromotive force was still high after the test. The results are also shown on Table 6.

Experiments with single oxidants continued to behave like the test without oxidant, while when using the mixture of oxidizing agents, it was possible to obtain a full recovery of the cerium dissolved in 2 stages of extraction, with the extraction of the other rare earth elements lower than $1 \%$, without the addition of the mixture in the second contact.

Experiments using a mixture of $\mathrm{Na}_{2} \mathrm{~S}_{2} \mathrm{O}_{8} / \mathrm{AgNO}_{3}$ gave similar results to those obtained for $\mathrm{K}_{2} \mathrm{~S}_{2} \mathrm{O}_{8} / \mathrm{AgNO}_{3}$, while for the mixture of $\left(\mathrm{NH}_{4}\right)_{2} \mathrm{~S}_{2} \mathrm{O}_{8} / \mathrm{AgNO}_{3}$ using the equivalent amount of persulfate ion used for $\mathrm{K}_{2} \mathrm{~S}_{2} \mathrm{O}_{8}$ and $\mathrm{Na}_{2} \mathrm{~S}_{2} \mathrm{O}_{8}$, the cerium extraction was $56 \%$, also without any extraction of other trivalent REE.

\subsection{Stripping}

In this step of the study, extraction experiments were carried out under the optimized conditions reached in the first step of this study using P507, obtaining an organic loaded solution that was then put in contact with stripping solutions of different compositions. Table 7 shows the rare earth elements content in the organic feed solution used in the stripping study.

In a first approach, the stripping solutions investigated were nitric and hydrochloric solutions, varying the concentration of the acid from 3.0 to $6.0 \mathrm{~mol} \cdot \mathrm{L}^{-1}$. For all of the 
stripping solution acidities, the stripping of the cerium was no higher than $3 \%$. This can be explained by the high affinity of cerium (IV) with cationic extractants, which confirms its selectivity in the extraction step.

Considering the difficulty in stripping Ce in the tetravalent state from a loaded P507, experiments were carried out by adding a reducing agent to the stripping solution to convert the cerium to its trivalent state and facilitate stripping. The reducing agent used was $10 \%$ hydrogen peroxide $\left(\mathrm{H}_{2} \mathrm{O}_{2}\right)$ [14], and the stripping solutions studied were nitric, sulfuric and hydrochloric acid solutions, all of them at a concentration of 1.0 $\mathrm{mol} \cdot \mathrm{L}^{-1}$. The results of these experiments are shown in Table 8 .

One can see that when the stripping experiments were carried out with the mixture of the acid and $\mathrm{H}_{2} \mathrm{O}_{2}$ less acidity of the stripping agent was required. While stripping solution acidity of $6.0 \mathrm{~mol} \cdot \mathrm{L}^{-1}$ did not show efficiency in stripping Ce (IV), when a reducing agent was used in the stripping solution, more than $99 \%$ of cerium was stripped in solution acidity of $1.0 \mathrm{~mol} \cdot \mathrm{L}^{-1}$ (Table 8 ).

\section{Conclusion}

The experiments without the oxidation of cerium (III) to cerium (IV) indicated the difficulty in its separation from the other trivalent REE. However, it was demonstrated that it is possible to obtain a high-grade, high-yield cerium product by the solvent extraction technique. Cerium was preferentially extracted rather than the other rare earths elements when oxidizes using a mixture of potassium persulfate and silver nitrate in nitric medium and P507 as extractant, achieving over $99.9 \%$ recovery with 99.9\% purity. Stripping experiments using the loaded organic from the extraction reached over $99 \%$ recovery of cerium when using hydrogen peroxide as reducing agent, with stripping solutions of nitric, hydrochloric or sulfuric acids.

\section{Acknowledgements}

The authors would like to acknowledge "INB-Indústrias Nucleares do Brasil S.A." for supplying the samples and the government agencies FAPEMIG, FINEP, CNPq and

Table 7. REE content on the loaded organic solutions.

\begin{tabular}{ccccccccc}
\hline \multirow{2}{*}{ Sample } & \multicolumn{10}{c}{ Content $(\mathrm{g} / \mathrm{L})$} \\
\cline { 2 - 9 } & $\mathrm{La}$ & $\mathrm{Ce}$ & $\mathrm{Nd}$ & $\mathrm{Pr}$ & $\mathrm{Sm}$ & $\mathrm{Gd}$ & $\mathrm{Dy}$ & $\mathrm{Y}$ \\
\hline \multirow{2}{*}{$\mathrm{P} 507$} & $<0.01$ & 20.9 & $<0.01$ & $<0.01$ & $<0.01$ & $<0.01$ & $<0.01$ & 0.03 \\
\hline
\end{tabular}

Table 8. Influence of the stripping solution on cerium recovery.

\begin{tabular}{ccc}
\hline Stripping solution & Reducing agent & Cerium recovery (\%) \\
\hline $\mathrm{HNO}_{3}$ & $\mathrm{H}_{2} \mathrm{O}_{2}$ & $>99$ \\
$\mathrm{H}_{2} \mathrm{SO}_{4}$ & $\mathrm{H}_{2} \mathrm{O}_{2}$ & $>99$ \\
$\mathrm{HCl}$ & $\mathrm{H}_{2} \mathrm{O}_{2}$ & $>99$ \\
\hline
\end{tabular}


CAPES for the financial support. Sincere thanks to CDTN technicians who were involved in this work.

\section{References}

[1] Kilbourn, B.T. (1993) A Lanthanide Lanthology. Molycorp Inc.

[2] Maestro, P. and Huguenin, D. (1995) Industrial Applications of Rare Earths: Which Way for the End of the Century? J. Alloys Compd, 225, 520-528.

http://dx.doi.org/10.1016/0925-8388(94)07095-4

[3] Abreu, R.D. and Morais, C.A. (2010) Purification of Rare Earth Elements from Monazite Sulphuric Acid Leach Liquor and the Production of High-Purity Ceric Oxide. Miner. Eng., 23, 536-540. http://dx.doi.org/10.1016/j.mineng.2010.03.010

[4] Gupta, C.K. and Krishnamurthy, N. (1992) Extractive Metallurgy of Rare Earths. CRC Press, 37. http://dx.doi.org/10.1179/imr.1992.37.1.197

[5] Habashi, F. (1997) Textbook of Hydrometallurgy. Laval University.

[6] Fritrz, J.S., et al. (1963) The Rare Earths and Rare-Earth Compounds, Treatise on Analytical Chemistry. John Wiley e Songs, Inc.

[7] Morais, C.A. (2004) Process Development for the Recovery of High-Grade Lanthanum by Solvent Extraction. Hydrometallurgy, 73, 237-244.

http://dx.doi.org/10.1016/j.hydromet.2003.10.008

[8] Zhang, D., et al. (2012) Extraction and Recovery of Cerium(IV) and Fluorine(I) from Sulfuric Solutions Using Bifunctional Ionic Liquid Extractants. Chem. Eng. J., 179, 19-25. http://dx.doi.org/10.1016/j.cej.2011.06.021

[9] Zhao, J., Zuo, Y., Li, D. and Liu, S. (2004) Extraction and Separation of Cerium(IV) from Nitric Acid Solutions Containing Thorium(IV) and Rare Earths(III) by DEHEHP. J. Alloys Compd., 374, 438-441. http://dx.doi.org/10.1016/j.jallcom.2003.11.057

[10] El-Hefny, N.E., El-Nadi, Y.A. and Ahmed, I.M. (2011) 18-Crown-6 for the Selective Extraction and Separation of Cerium(IV) from Nitrate Medium Containing Some Lanthanides. Int. J. Miner. Process., 101, 58-62. http://dx.doi.org/10.1016/j.minpro.2011.07.013

[11] Amaral, J.C.B.S. and Morais, C.A. (2010) Thorium and Uranium Extraction from Rare Earth Elements in Monazite Sulfuricacid Liquor through Solvent Extraction. Miner. Eng., 23, 498-503. http://dx.doi.org/10.1016/j.mineng.2010.01.003

[12] Abreu, R.D. and Morais, C.A. (2014) Study on Separation of Heavy Rare Earth Elements by Solvent Extraction with Organophosphorus Acids and Amine Reagents. Miner. Eng., 61, 82-87. http://dx.doi.org/10.1016/j.mineng.2014.03.015

[13] Skarewski, J. (1984) Cerium Catalyzed Persulfate Oxidation of Polycyclic Aromatic Hydrocarbons to Quinones. Tetrahedron, 40, 4997-5000. http://dx.doi.org/10.1016/S0040-4020(01)91339-0

[14] Preston, J.S. (1996) The Recovery of Rare Earth Oxides from a Phosphoric Acid Byproduct. Part 4. The Preparation of Magnet-Grade Neodymium Oxide from the Light Rare Earth Fraction. Hydrometallurgy, 42, 151-167. http://dx.doi.org/10.1016/0304-386X(95)00082-R 
Submit or recommend next manuscript to SCIRP and we will provide best service for you:

Accepting pre-submission inquiries through Email, Facebook, LinkedIn, Twitter, etc. A wide selection of journals (inclusive of 9 subjects, more than 200 journals)

Providing 24-hour high-quality service

User-friendly online submission system

Fair and swift peer-review system

Efficient typesetting and proofreading procedure

Display of the result of downloads and visits, as well as the number of cited articles

Maximum dissemination of your research work

Submit your manuscript at: http://papersubmission.scirp.org/

Orcontactwjet@scirp.org 